\title{
Augusto en las primeras historias de España y en los programas iconográficos del Renacimiento*
}

Gloria Mora

\section{Universidad Autónoma de Madrid}

gloria.mora@uam.es

\section{Fecha recepción 09.01.2017 / Fecha aceptación 09.03.2017}

\section{Resumen}

Es frecuente en las historias de España la alusión a ciertos personajes de la historia de Roma destacando el papel fundamental que desempeñaron en la historia antigua de España y de la misma Roma, como César, fundador de ciudades, o Trajano y los llamados «emperadores españoles». El propósito de este trabajo es rastrear el tratamiento que recibió Augusto en la historiografía española de época medieval y del Renacimiento desde las crónicas de Lucas de Tuy, Rodrigo Ximénez de Rada y las Es-

\begin{abstract}
It is common in Spanish historiography to allude to certain characters in the history of Rome by highlighting their crucial role in the ancient history of Spain and in Rome itself, e.g., Caesar, founder of cities, or Trajan and the so-called "Spanish emperors". The purpose of this paper is to follow the treatment received by Augustus in the Spanish historiography of the Middle Ages and the Renaissance using the chronicles of Lucas de Tuy, Rodrigo Ximénez de Rada, the Estorias of Alfonso
\end{abstract}

* Este trabajo se enmarca en el proyecto HAR 2012-31736. 
Monográfico | Augusto en las primeras historias de España y en los programas iconográficos del Renacimiento

torias de Alfonso X el Sabio hasta los relatos de los cronistas reales Elio Antonio de Nebrija, Florián de Ocampo y Ambrosio de Morales. Se estudiará también la presencia de Augusto en las colecciones y los programas iconográficos de la monarquía.

\section{Palabras clave}

Augusto. Historiografía española. Programas iconográficos del Renacimiento. Coleccionismo de antigüedades.
$\mathrm{X}$ the Wise, and the stories of the royal chroniclers Elio Antonio de Nebrija, Florián de Ocampo and Ambrosio de Morales. The presence of Augustus in collections and iconographic programmes of the monarchy is also studied.

\section{Key words}

Augustus. Spanish Historiography. Iconographic programs of the Renaissance. Collection of antiquities. 
En 1574 Y 1577, el Cronista real Ambrosio de Morales publicó en Alcalá de Henares la segunda parte de la Coronica General de España iniciada por Florián de Ocampo, que se había interrumpido en la llegada de los romanos a España y el inicio de la II Guerra Púnica, llegando «hasta que [España] fue destruyda por los Moros». La crónica de Ocampo es la primera que recurre a fuentes materiales (inscripciones sobre todo) para reforzar su relato de los hechos, pero la de Morales es la primera historia de España que narra los acontecimientos con rigor, rechazando leyendas y tradiciones y utilizando ampliamente fuentes textuales y materiales (epigrafía, numismática, monumentos, análisis de la toponimia, etc.), dedicando incluso un libro específico a la «averiguación» de Las antigüedades de España que van nombradas en la Coronica (Alcalá de Henares, 1575).

Con la Coronica de Morales culmina una tradición muy anterior y se abre una nueva etapa, marcada por el mayor cuidado en la selección e interpretación de las fuentes y coincidiendo justamente con los primeros estudios de tipo anticuario-arqueológico, como los del propio Morales o los de Antonio Agustín ${ }^{1}$.

El propósito de este texto es rastrear, en una primera aproximación, el tratamiento que recibió Augusto en la historiografía española bajomedieval y renacentista. El arco cronológico considerado comprende desde las primeras crónicas e historias generales del siglo XIII - el Chronicon Mundi de Lucas de Tuy, De rebus Hispaniae de Rodrigo Ximénez de Rada, las Estorias de Alfonso X el Sabio -, hasta las obras de los primeros cronistas reales de los Austrias (Elio Antonio de Nebrija, Florián de Ocampo, Ambrosio de Morales), durante el siglo XVI, coincidiendo con el auge del Imperio español, en las que se hace referencia constante al Imperio Romano como modelo de la monarquía hispánica². En ellas se expresan ya los

1. La bibliografía sobre los estudios anticuarios y sus protagonistas en esta época es muy abundante; remito a M. Díaz-Andreu, G. Mora y J. Cortadella (eds.), Diccionario Histórico de la Arqueología en España, Madrid, 2009.

2. He seleccionado algunas de las Crónicas e Historias que me han parecido más significativas. En general, sobre la historiografía del siglo XVI: F. Wulff, Las esencias patrias. Historiografía e Historia Antigua en la construcción de la identidad española (siglos XVI-XX), Barcelona, 2003, cap. 1: “La nueva España”, y B. Cuart Moner, "La larga marcha hacia las historias de España en el siglo XVI", en R. García Cárcel (coord.), La construcción de las Historias de España, Madrid, 2004, cap. 1. 
topoi de la historiografía hispana posterior, a veces contradictorios pero siempre efectivos: el papel de Hispania en el Imperio Romano y los emperadores «españoles», la Era Hispánica o de Augusto «inventada» por los hispanos, las virtudes de los primitivos habitantes de la Península Ibérica como exempla principis. Se tendrán en cuenta también a otros autores como Esteban de Garibay y Juan de Mariana, así como una curiosa mención de Juan Páez de Castro en el Memorial que dirigió a Felipe II a propósito de la biblioteca de El Escorial. Por el contrario, no trataremos la obra de algunos humanistas importantes pero que no aportan nada interesante al tema que tratamos, aunque sí para la historia de la arqueología en España, como Lucio Marineo Sículo o Lorenzo de Padilla. Por otro lado, el acercamiento al tema implica dos líneas de investigación principales: Augusto en la historiografía, y Augusto en el coleccionismo de antigüedades y en los programas iconográficos de trasfondo ideológico elaborados para la propaganda política de los Austrias en el siglo XVI. En relación al tema concreto de este trabajo, podemos preguntarnos si Augusto es - y hasta qué punto lo es - uno de los personajes históricos favoritos de los historiadores como modelo o referente, y, en caso afirmativo, si encontramos un reflejo de ello en las colecciones de antigüedades hispanas o en los programas iconográficos del Renacimiento.

En la historiografía española renacentista relativa a los tiempos antiguos de la historia de España convergen una serie de historias y crónicas anteriores escritas a partir del siglo XIII pero con raíces más antiguas que se remontan a Isidoro de Sevilla. Más allá de los complejos estudios filológicos sobre las distintas versiones, manuscritos, las relaciones de dependencia entre ellos, etc., podemos intentar hallar un hilo conductor en la acumulación progresiva de fuentes hasta llegar a la construcción de la historia de España en la etapa romana, que es la que ahora nos interesa, y, más concretamente, el papel de Augusto en ella.

Lo que resulta evidente al leer estos primeros relatos es que la historia de España se entiende, por una parte, como inextricablemente unida a la historia universal según el modelo establecido por Eusebio de Cesarea y los primeros historiadores cristianos, fundamentalmente Paulo Orosio, y transmitido por Isidoro de Sevilla; por otra, como la historia de un territorio, la Península Ibérica, y de los pueblos que habitaron en ella, más que la de una monarquía. Y, finalmente, domina la concepción del pasado como origen y modelo, pero también explicación, del presente. Es frecuente en estas historias la alusión a ciertos personajes de la historia romana destacando el papel fundamental que desempeñaron en la historia antigua de España y en la de la misma Roma, como César, fundador de ciudades en la Península Ibérica, o Trajano y los llamados emperadores «españoles», especialmente Marco Aurelio, espejo para la educación del príncipe Felipe según el tratado de Antonio de Guevara, Relox de príncipes, de 1528.

Como se ha dicho, en la historiografía medieval las fuentes se transmiten de un autor a otro. No es necesario haber leído directamente a los autores antiguos (Livio, Suetonio) para citarlos a través de las interpretaciones expuestas por historiadores cristianos como Eusebio de Cesarea, Jerónimo, Paulo Orosio o Hidacio, y sobre todo a través de Isidoro de Sevilla, cuya Historia Gothorum fue el modelo para las historias nacionales, y de la llamada Chronica pseudo-isidoriana del siglo XII. Por otro lado, el modelo de historia universal proporcionado por los primeros historiadores cristianos, en la que se integra la historiografía de España, se va depurando hasta invertir los términos, llegando la historia de España a representar un 
papel protagonista en la historia universal o a defender el papel de España en el dominio del resto del mundo desde el origen de los tiempos.

Por lo que respecta a las fuentes, entre los historiadores grecolatinos predominan César, Livio y Floro, Suetonio, Tácito, los dos Plinio, Dion Casio, Lucano, y Flavio Josefo, pero sobre todo a través de la Crónica de Eusebio de Cesarea, S. Jerónimo y Paulo Orosio, en muchos casos a través de la Historia (de regibus) Gothorum, Vandalorum et Suevorum de Isidoro de Sevilla, redactada hacia 624 por encargo de Sisebuto, que constituye el modelo de la historiografía posterior tanto en estructura como en finalidad: la exaltación del reino visigodo como heredero de Roma, situándolo en un marco universal y defendiendo la unidad de España y la identidad gótica frente al Imperio Bizantino ${ }^{3}$. Sus fuentes: S. Jerónimo (continuador de la Chronica de Eusebio de Cesarea, 378), Orosio (hasta 417) e Hidacio (hasta 469) y Juan de Bíclaro (565-590).

A partir de Isidoro se constata la influencia de unas crónicas e historias sobre otras, coetáneas o posteriores, a veces copiando literalmente fragmentos como en el caso de Juan de Mariana respecto a Esteban de Garibay. La secuencia de continuidad y dependencia de estos relatos sería la siguiente: Crónica albeldense (s. IX) - refundición mozárabe de las Historiae de Orosio (s. X) - Crónica pseudo-isidoriana (mediados del siglo XII) - Crónica najerense (s. XII) - Lucas de Tuy (1236/38) y Rodrigo Ximénez de Rada (1243 la versión latina, 1253/54 la castellana) - Estorias de Alfonso X (1284) - Joan Margarit (s. XV) - Elio Antonio de Nebrija (1498/99) - Florián de Ocampo (1543 y 1553) - Esteban de Garibay (1571) - Ambrosio de Morales (1574 y 1577) - Juan de Mariana (1592).

Al mismo tiempo hay que tener en cuenta la influencia de las fuentes árabes, especialmente en el caso de la Crónica pseudo-isidoriana y su dependencia de la Historia de los reyes de al-Andalus de al-Razi (s. X) $)^{5}$. Precisamente esta Crónica, que abarca la historia de Hispania desde los orígenes hasta la conquista árabe y fue editada por primera vez por Theodor Mommsen en 1894, constituye uno de los testimonios fundamentales del género de las historias generales de España que se desarrollan en época medieval y culminan en el proyecto historiográfico de Alfonso $\mathrm{X}^{6}$. En ella aparecen ya algunos de los temas que se repetirán posteriormente en relación con Augusto, como su vinculación a César en Hispania, las

3. F. González Muñoz, La Chronica Gothorum pseudo-isidoriana (Ms. Paris BN 6113). Edición crítica, traducción y estudio, A Coruña, 2000, 12. Sobre Isidoro, véase recientemente el monográfico coordinado por I. Velázquez y G. Ripoll Isidore de Séville et son temps, AnTard, 23, 2015; en pp. 249-268, texto de E. Falque sobre Isidoro en Lucas de Tuy. Sobre Suetonio en España: M. Conde Salazar, "La progresiva evolución de las biografías de Suetonio transmitidas en las ediciones incunables de las Vitae duodecim Caesarum”, en J.A. Beltrán et al. (eds.), Otium cum dignitate. Estudios en homenaje al profesor Javier Iso Echegoyen, Zaragoza, 2013, 391-401.

4. En general, cf. M. Huete Fudio, La historiografía latina medieval en la Península Ibérica (siglos VIIIXII). Fuentes y bibliografía, Madrid, 1997; Cuart Moner, "La larga marcha...", op. cit., 46-126.

5. González Muñoz, La Chronica..., op. cit., 13. Acerca de la influencia de las fuentes árabes en la historiografía hispana bajomedieval, véase J. Elices Ocón, El pasado preislámico en al-Andalus: fuentes árabes, recepción de la Antigüedad y legitimación en época omeya (ss. VIII-X), Tesis Doctoral, UAM, 2017.

6. González Muñoz, La Chronica..., op. cit., 11. 
fundaciones de ambos o el origen de la Era Hispánica o de Augusto, así como menciones a monumentos romanos representativos de la antigüedad de España (como el llamado «Ídolo de Cádiz» o «Torre de Hércules») que serán recogidos después en las Historias alfonsíes.

Empezamos con las crónicas e historias de mediados del siglo XIII relacionadas con Alfonso X el Sabio: el Chronicon Mundi de Lucas de Tuy y De rebus Hispaniae de Ximénez de Rada, que son prácticamente contemporáneos aunque el segundo depende del primero; ambos influyeron en las Estorias de Alfonso $\mathrm{X}^{8}$.

Lucas de Tuy, el Tudense, canónigo de San Isidoro de León y obispo de León, escribió su Chronicon mundi hacia 1236-1238 por encargo de Berenguela de Castilla, madre de Fernando III, inspirándose en la Historia Gothorum de Isidoro de Sevilla, su principal fuente junto a Hidacio, Paulo Orosio, Pedro Coméstor, Juan de Bíclaro y la Crónica najerense ${ }^{9}$. El arco cronológico abarca desde la antigüedad hasta 1236, año de la conquista de Córdoba por Fernando III el Santo. Como se ha dicho, es coetáneo de De rebus Hispaniae o Rerum in Hispania gestarum chronicon de Rodrigo Ximénez de Rada, arzobispo de Toledo; ambas obras defendían la supremacía de la monarquía en una España unificada, pero por intereses políticos la crónica del Tudense alcanzó mucha menor fortuna, ya que Lucas defendía la primacía de la sede episcopal de Sevilla como sede metropolitana frente a la opinión de Ximénez de Rada, quien lógicamente optaba por la de Toledo, que era la elegida por Alfonso $\mathrm{X}$ y la que finalmente triunfó ${ }^{10}$.

El Libro I del Chronicon (92-99) está dedicado a los emperadores romanos (hasta principios del s. VI con Heraclio y Suintila). Sigue a Isidoro en el planteamiento y exposición de algunos temas que se repetirán en la historiografía posterior: el protagonismo de César, su lucha contra Pompeyo en Hispania y la fundación de ciudades; el papel histórico de «Octaviano Augusto», durante cuyo gobierno tuvo lugar el nacimiento de Cristo, con alusión a la nueva edad de oro profetizada por Virgilio en su IV Égloga, y la mención a la Era Hispánica como sistema de datación propio de los españoles. Se trata de una historia universal y peninsular, que privilegia la hispánica según el modelo de historia nacionalista de Isidoro ${ }^{11}$; también es una historia providencialista que recoge la leyenda de la fundación de Roma

7. González Muñoz, La Chronica..., op. cit., 19, 27-28, 46. Este «ídolo de Cádiz» sería en realidad una estructura coronada por una estatua colosal, quizá de Adriano, identificada como Hércules, el fundador de la ciudad: González Muñoz, La Chronica..., op. cit., 27-28; J. Carracedo Fraga, "La Torre de Cádiz: un monumento de la Antigüedad clásica en textos medievales”, Evphrosyne. Revista de filología clássica, 19, 1991, 201-230.

8. L. Fernández Gallardo, "De Lucas de Tuy a Alfonso el Sabio: idea de la Historia y proyecto historiográfico", Revista de poética medieval, 12, 2004, 53-119.

9. E. Jerez Cabrero, El Chronicon mundi de Lucas de Tuy (c. 1238): técnicas compositivas y motivaciones ideológicas, Tesis Doctoral UAM, Madrid, 2006. Sobre Lucas historiador: pp. 161 ss.; sobre sus fuentes: pp. 172 ss.

10. Jerez Cabrero, El Chronicon..., op. cit., pp. 180 ss.; P. Linehan, "Lucas de Tuy, Rodrigo Ximénez de Rada y las historias alfonsíes”, en I. Fernández-Ordóñez (ed.), Alfonso X el Sabio y las Crónicas de España, Valladolid, 2000, $27 \mathrm{~s}$.

11. Jerez Cabrero, El Chronicon..., op. cit., 167. 
por Rómulo y Remo, milagrosamente salvados por la loba, por su relación con la existencia de la «santa Roma» ${ }^{12}$. Y además tiene una finalidad pedagógica anticipando el género de la historia como speculum principis característico del Renacimiento, ya que, según se ha sugerido, presenta modelos de virtudes para seguir y ejemplos de vicios y defectos que rechazar destinados a la educación del futuro Alfonso $\mathrm{X}^{13}$. En palabras de Enrique Jerez Cabrero, hay que reconocer la «deuda que la ficción de inspiración histórica alumbrada en la Edad Media peninsular tiene contraída con don Lucas» ${ }^{14}$.

Unos años después, Fernando III, padre de Alfonso X, encargó a Rodrigo Ximénez de Rada, arzobispo de Toledo, una historia de España que tratase de antiquitatibus Hispaniae et de iis etiam quae ab antiquis ver modernis temporibus acciderunt y a quibus gentibus calamitatis Hispania sit perpessa, et Hispanorum Regum origo. Rada siguió el modelo de la Historia Gothorum... ideado por Isidoro de Sevilla para la Hispania de Sisebuto y Suintila a comienzos del s. VII ${ }^{15}$. Ximénez de Rada expuso en ella un programa ideológico cuyo objetivo era crear «un imaginario mítico peculiar a la Castilla que quiere ser escenario de una monarquía renovada por su vocación integradora ${ }^{16}$.

De rebus Hispaniae o Historia de rebus Hispanie sive Historia Gothica, de 1243 (editada por Juan Fernández Valverde en 1987) se puede considerar la primera historia de España, según Diego Catalán. De ella deriva la Estoria de los godos (ca. 1252/53), que incluye préstamos del Chronicon mundi de Lucas de Tuy ${ }^{17}$.

En su primera redacción, De rebus Hispaniae estaba formada por la Historia Gothica y la Historia Romanorum. En la introducción de la Historia Gothica, dedicada a los orígenes de España, se habla de los fundadores de los pueblos y ciudades de la Península, mezclando mitos con realidad histórica: Hércules, fundador de Híspalis, Gerión, etc.; de los «castiellos» (en el original latino: oppida) de la Carpentania (sic): Aucam, Calagurram, Tirasonam et Auripam (Auca, Calafarta, Taraçona y Auripa) que post Cesaraugusta ab Augusto Cesare fuit dicta, uis Romanorum principum occupauit, que tamen, sicunt refferunt Plinius et Sisebutus, ad Cartaginensem prouinciam pertinebat ${ }^{18}$. La Historia Romanorum es una obra menor cuyas

12. Jerez Cabrero, El Chronicon..., op. cit., 230-235.

13. Jerez Cabrero, El Chronicon..., op. cit., 171, 190-191 y n. 506.

14. Jerez Cabrero, El Chronicon..., op. cit., 5.

15. D. Catalán, La Estoria de España de Alfonso X. Creación y evolución, Madrid, 1992, 29. Al parecer Ximénez de Rada no utilizó la Crónica pseudo-isidoriana como fuente; según González Muñoz, La Chronica..., op. cit., 95, las coincidencias entre ambos relatos proceden de la Historia de los reyes de alAndalus de al-Razi.

16. F.J. Peña Pérez, "Nuño Rasura y Laín Calvo. Los orígenes del pensamiento mítico sobre Castilla”, en J.A. Munita Loinaz (ed.), Mitificadores del pasado, falsarios de la Historia. Historia Medieval, Moderna y de América, Bilbao, 2011, 64.

17. Parece que Ambrosio de Morales conoció el manuscrito borrador original, hoy perdido, que se encontraba en el monasterio de Santa María de Huerta, cerca de Medinaceli, donde Ximénez de Rada pasó mucho tiempo al final de su vida, pues lo cita en su Coronica (lib. III, Alcalá, 1574, fol. 191): cf. D. Catalán, "Rodericus" romanzado en los reinos de Aragón, Castilla y Navarra, Madrid, 2005, 18-19.

18. Catalán, "Rodericus"..., op. cit., 662-663. 
fuentes son Livio, Lucano, Ovidio, Virgilio y, sobre todo, Paulo Orosio y Paulo Diácono (que sigue a Orosio ${ }^{19}$. Siguiendo la tradición analística, es una historia de Roma desde la llegada de Eneas al Lacio pero siempre en relación a la historia de España, como se dice en el Prólogo. Termina con la victoria de César en la batalla de Munda tras cuatro años de guerra civil, y su regreso a Roma para morir a manos de los senadores. Esta parquedad contrasta con la larga disquisición sobre las diferentes identificaciones de Munda, problema que preocupa ya y preocupará en el futuro a todos los historiadores españoles, pues consideraron que en esta batalla dada en suelo hispano se decidió el destino de Roma y del mundo. Pero no se menciona la presencia de Octaviano en la batalla.

Ambas crónicas, la de Lucas de Tuy y la de Ximénez de Rada, confluyeron en la primera gran historia nacional, ya que fueron utilizadas como fuente de la Estoria de España, una de las obras elaboradas en el taller historiográfico de Alfonso X el Sabio como argumento de apoyo a sus pretensiones al trono imperial del Sacro Imperio Romano Germánico: «en rrazon de enperio ${ }^{20}$. Y es precisamente a partir de las Estorias de Alfonso X cuando se acentúa la idea de Augusto como pacificador y unificador.

La General e grand Estoria (o Grande e general estoria) y la Estoria General de España fueron redactadas simultáneamente. Se conservan diferentes versiones manuscritas que han sido estudiadas por Ramón Menéndez Pidal, Diego Catalán, Georges Martin, Peter Linehan, Inés Fernández-Ordóñez y Mariano de la Campa, entre otros. La Estoria de España fue compuesta antes de 1271 y quedó inconclusa. Nos interesa la llamada «Versión regia o crítica», que abarca la historia antigua, la historia gótica y la de la monarquía astur-leonesa hasta mediados del reinado de Alfonso II el Casto, en tanto que la «Versión primitiva» relata los acontecimientos desde el reinado de Ramiro I hasta el final de la monarquía leonesa con Vermudo III ${ }^{21}$. La Grande e general Estoria se redactó entre ca. 1270 y 1284, año de la muerte de Alfonso, y tampoco se terminó ${ }^{2}$. Es una historia universal desde la creación que según el proyecto llegaría hasta el reinado de Alfonso X, en seis partes, pero el relato se interrumpe en la sexta parte al narrar la vida de los padres de la Virgen, completándose el relato bíblico con otros acontecimientos de la historia de los «gentiles». Las fuentes son muy variadas: el Antiguo Testamento, la Crónica de Eusebio de Cesarea en la versión ampliada de San Jerónimo y otras fuentes grecolatinas (Flavio Josefo, Lucano, Ovidio), Pedro Coméstor, Geoffrey de Monmouth... En la $5^{\text {a }}$ parte, tras narrar el cautiverio de Babilonia y la historia de los Macabeos, se menciona el Mandato de Julio César y Mandato de Octavio Augusto. De la $6^{\text {a }}$ parte se

19. J. Fernández Valverde, "Roderici Ximenii de Rada Historia Romanorum”, Habis, X-XI, 1979-80, 158.

20. Cit. por D. Catalán, La Estoria..., op. cit., 44. G. Martin, "El modelo historiográfico alfonsí y sus antecedentes", en Fernández-Ordóñez (ed.), Alfonso X el Sabio..., op. cit., 37-59.

21. M. de la Campa, La Estoria de España de Alfonso X. Estudio y edición de la Versión Crítica desde Fruela II hasta la muerte de Fernando II, Málaga, 2009, 29.

22. Alfonso X el Sabio, General Estoria, P. Sánchez-Prieto Borja (coord. de la edición íntegra), Madrid, 2009, 10 vols. 
conserva sólo el inicio del Imperio de Octavio César en Roma en un fragmento de borrador de 20 folios (ms. 43-20 del Archivo Capitular de la Catedral de Toledo) ${ }^{23}$.

En la General Estoria se repiten temas que ya aparecían en Lucas de Tuy y Ximénez de Rada, y que, desarrollados, van a estar muy presentes en la historiografía posterior: «Augusto César» como uno de los personajes importantes de la Historia, incluido entre los «reyes gentiles» junto a Darío, Alejandro el Grande, Artajerjes y Julio César; y la alusión a la Era Hispánica o Era de Augusto, que, como veremos, Esteban de Garibay primero y Ambrosio de Morales después explicarán como el sistema de datación elegido por los hispanos para honrar a Augusto tomando como punto de partida la fecha del fin del segundo triunvirato en 38 a.C.

Estas historias tienen su continuidad en el Renacimiento, pero con matices humanistas representados por un mejor conocimiento y uso de las fuentes literarias, el añadido de las materiales (inscripciones, monedas y monumentos) y su aplicación a los programas iconográficos elaborados para mayor gloria y propaganda política de la monarquía.

Un primer ejemplo lo constituye la obra del humanista Joan Margarit y Pau en época de Alfonso V el Magnánimo: su Paralipomenon Hispaniae consta de diez libros sobre la historia de España desde sus orígenes (no fue publicado hasta 1545, por Sancho Nebrija en Granada ${ }^{24}$. Pretendía llegar hasta Teodosio y la división del Imperio, pero lo dejó inacabado a su muerte en el libro X, correspondiente a la estancia de Augusto en Hispania. Margarit insiste en demostrar que el Edicto promulgado por Augusto sobre el censo de todos los habitantes del Imperio se dio en Tarragona después de la guerra y victoria sobre los cántabros, astures y vacceos (Datum Tarragona, según la tradición que partía de Floro y Orosio), quizá para enfatizar el papel de la Corona de Aragón (y de Cataluña) frente a la de Castilla, aportando un dato tan relevante para la historia del cristianismo - que será negado después por Ambrosio de Morales. También introduce otro de los temas capitales de la historiografía española: el cierre de las puertas del templo de Jano (Et haec de perpetua \& aeterna pace...).

Más cercano a Castilla que a Aragón está Elio Antonio de Nebrija, primer cronista real nombrado por Fernando el Católico en 1509. Ya en su Gramática de la lengua castellana presentaba a los Reyes Católicos como restauradores del Imperium Hispaniae mediante la imposición de la unidad territorial, religiosa y lingüística, que equivalía a la Pax de Augusto. La Muestra de la istoria delas antigüedades de España (Burgos, Fadrique de Basilea, ca. 14981499 o 1491$)^{25}$ es una obra inacabada (sólo redactó el libro I) dedicada a Isabel la Católica, quien se la había encargado según él mismo dice en el párrafo introductorio. El plan consistía en cuatro libros de historia desde «las cosas mas antiguas de España» (I) hasta la expulsión de los romanos por los godos (IV), seguidos de un quinto libro «de los varones mas señalados en

23. Ed. de P. Sánchez-Prieto Borja y B. Almeida en Sánchez-Prieto Borja (coord.), Alfonso X el Sabio, General Estoria..., op. cit.

24. R. Tate, Joan Margarit i Pau, cardenal i bisbe de Girona, Barcelona, 1976.

25. Muestra dela historia que Maestro de Lebrixa dio ala Reina nuestra señora: quando pidió licencia a su alteza para que pudiesse descubrir i sacar a luz las antigüedades de españa que hasta nuestros días an estado encubiertas i para que pudiesse como dize Vergilio. Pandere res alta terra \& calígine mersas (Virg., En., VI, 267). Edición de I. González Llubera, Oxford 1926, 203-228; también V. Bonmatí y F. Álvarez en Nebrija historiador (estudio preliminar, traducción y notas), Lebrija, 1992, 79-105. 
letras que ouo en España i algunos principes allêde los que enlos libros pasados diximos». El libro III estaría dedicado a las cosas que hicieron en España César y Pompeyo continuando hasta el primer año de Tiberio. Las fuentes utilizadas son abundantes, tanto griegas como romanas, divididas en cosmógrafos, «istóricos», poetas y «otros escritores» que aparecen enumerados en página aparte a continuación del índice, aunque sólo los relativos al libro I.

En la lista de historiadores oficiales podemos mencionar también a Lorenzo de Padilla (1485-1540), arcediano de Ronda ${ }^{26}$ y cronista de Carlos V desde 1538, en cuyo Libro de las Antigüedades de España (ms. de 1538 publicado en Valencia en 1669) utiliza mucha epigrafía latina ${ }^{27}$. Pero son los siguientes cronistas, Florián de Ocampo y, sobre todo, Ambrosio de Morales, quienes llevarán la historiografía a un nivel profesional.

En efecto, la gran historiografía del siglo XVI es fruto de una empresa oficial y de dos iniciativas particulares. En primer lugar, Florián de Ocampo, quien fue designado cronista real en 1539, sucediendo en el cargo a Padilla, editó la Estoria General de España de Alfonso X con el título de Chronica General Vulgata (Zamora, 1541) y se propuso escribir - como declara en el prólogo - una historia de la España antigua «digna de la majestad de la contemporánea», el Imperio español de Carlos V. Los quatro libros primeros de la cronica general de España se publicaron en 1543 en Zamora, y diez años después, en Medina del Campo, Los cinco libros primeros. Esta Crónica quedó inconclusa, llegando sólo al comienzo de la Segunda Guerra Púnica, pero en ella se proponían ya temas propiamente renacentistas como la identificación de las virtudes y triunfos de Carlos con los de algunos gobernantes y emperadores romanos, especialmente César, Augusto, Trajano y Constantino ${ }^{28}$. También aparecía la mención a la Pax Augusta equiparada a la «universalidad cristiana» impuesta por los Reyes Católicos, rota con la Reforma protestante, y a los turcos como nuevos bárbaros. Ocampo pone la Historia Antigua (mediante textos y epígrafes) al servicio de la idea imperial, por ejemplo para defender los derechos de Carlos en territorios como Marsella o el Condado del Rosellón, en disputa con Francia ${ }^{29}$.

Continuador de la Crónica de Florián de Ocampo fue Ambrosio de Morales, cronista de Felipe II, con La Coronica general de España que continuaba Ambrosio de Morales (1575). Pero entre ambos se redacta la Historia de España de Esteban de Garibay y Zamalloa, Los Quarenta libros del Compendio historial de las Chronicas y Universal Historia de todos los Reynos de España, obra dedicada a Felipe II, quien en 1592 concederá a Garibay el título de

26. No debe confundirse con el Lorenzo de Padilla, también arcediano de Ronda, que denunció a Jerónimo Zurita.

27. V. Salamanqués Pérez y E. Sánchez Medina, "Aportaciones bio-bibliográficas sobre Lorenzo de Padilla: sus Antigüedades de España y la epigrafía votiva”, en J.Ma Maestre, J. Pascual Barea y L. Charlo Brea (eds.), Humanismo y pervivencia del mundo clásico. Homenaje al profesor Antonio Prieto, Madrid, 2008, IV, 23052319.

28. F. Checa Cremades, Carlos V y la imagen del héroe en el Renacimiento, Madrid 1987; P. Gabaudan, El mito imperial. Estudio iconológico de los relieves de la Universidad salmantina, Madrid, 2012.

29. $M^{a}$ del M. de Bustos Guadaño, "La Crónica de Ocampo y la tradición alfonsí en el siglo XVI", en Fernández-Ordóñez (ed.), Alfonso X el Sabio..., op. cit., 196-197. 
cronista $^{30}$. En el «Prólogo a su Catholica Majestad» considera a César el primer emperador de los romanos (siguiendo la tradición derivada de Suetonio), pero usurpador del título a diferencia de Felipe, que merece «título tan benemérito [...] por diversas y justas causas». En los ocho libros primeros narra «las cosas mas memorables de España, desde la creación del mundo, hasta la fin de la historia de los Reyes Godos», correspondiendo el capítulo XXV del libro sexto a «Octaviano Augusto César Segundo, Emperador de Roma, Señor de España», venerado por los españoles: «Quedaron en España grandes señales de auer sido las cosas de Octauiano Augusto Cesar mas celebradas y amadas en los coraçones de la nación Española, que las de ningun otro Emperador sucesor suyo, ni las de ningun otro Principe Romano su predecessor», como demuestra la instauración de la Era de César o Era Hispánica como cronología en honor a la fundación del segundo triunvirato, según la explicación de Garibay (lib. VI, cap. XXVI) y otros historiadores ${ }^{31}$.

Garibay fue una de las fuentes de La Coronica General de España que continuaba Ambrosio de Morales (1575), ya citada. Morales empezó su obra en el punto en que la había dejado Ocampo y llegó hasta principios del siglo XI, con la unión de Castilla y León con Fernando I tras la muerte de Vermudo III. En la Dedicatoria a Felipe II, siguiendo a Nebrija, declaraba su propósito de escribir un capítulo de la historia de España que consideraba inexistente hasta ese momento, el de la España antigua, pues en su opinión las historias anteriores se centraban en las épocas visigoda y medieval. «Porque todos los hombres generalmente son aficionados a saber las cosas de su tierra: y con mucha mas razón lo debemos ser los Españoles, pues en todos los siglos hemos tenido tan señaladas, y tan dignas de que todos las sepan, para tomar ejemplo en ellas de religión, de grandeza de ánimo, de esfuerzo y lealtad». Precisamente Morales pretendía proporcionar a Felipe II una serie de estos ejemplos «de grandeza de ánimo, de esfuerzo y lealtad» para su gobierno; en este sentido, la obra complementaba el Relox de príncipes de Antonio de Guevara (1528), que presentaba a Marco Aurelio como espejo de virtudes para el príncipe Felipe ${ }^{32}$. Para Morales, como para Nebrija anteriormente, la España de Felipe equivalía a la Hispania romana, lo que concuerda con los mapas realizados por el cartógrafo real Abraham Ortelius y con otros proyectos de averiguación de las antigüedades de España como las Relaciones Topográficas de los Pueblos de España. Por ello recurrió a textos y documentos materiales: inscripciones, monedas, monumentos y ruinas e identificación de lugares; por ejemplo, dedica el cap. LV del lib. VIII a la recopilación de epígrafes hispanos de época de Augusto. El relato correspondiente al Princeps (lib. VIII, cap. LI a LIX) es similar al de Garibay, recogiendo las guerras cántabras, la fundación de ciudades, el establecimiento

30. El Compendio historial fue publicado primero por Plantino en Amberes en 1571 o 1570-2, y después en Barcelona, por Sebastián de Cormellas, en 1628 (tras censura de Juan Páez de Castro, también cronista de S.M., fechada en 1627), que es la edición que hemos utilizado.

31. E. de Garibay, Los Quarenta libros del Compendio historial..., I, lib. VI, Barcelona, 1628, 171-173. Sin embargo, considera que el mejor de los emperadores había sido Trajano «por lo qual no es pequeña la gloria, que a España cabe» (cap. XIII, 197).

32. En cambio, para Honorato Juan, preceptor del príncipe Felipe y después de Don Carlos, el modelo era Carlomagno, con quien compara al emperador Carlos (según anotaciones en su ejemplar de la Vita Karoli de Eginardo). 
de la Era de César y otros hechos señalados de Augusto en Hispania, pero rechazando por falsa la tesis del edicto de empadronamiento dado en Tarragona (cap. LVIII).

La última gran historia de España del siglo XVI es la de Juan de Mariana, también dedicada a Felipe $\mathrm{II}^{33}$. La Historia general de España escrita primero en latín (Historiae de rebus Hispaniae libri XXV, 1592) y traducida por él mismo, es probablemente la obra más influyente de la historiografía española hasta la Historia de España de Modesto Lafuente, a juzgar por sus diversas ediciones hasta el siglo XIX ${ }^{34}$. Abarca desde el origen de la población de España hasta la muerte de Fernando el Católico; según su declaración, no sigue adelante por prudencia. Una de sus fuentes es Ambrosio de Morales, "persona en lo demás docta y diligente en rastrear las antigüedades de España» (lib. III, cap. XIV, 75), pero recurre, sobre todo, a Esteban de Garibay, a quien copia literalmente en algunos pasajes. Así, en el prólogo (pp. LI s.), plantea su Historia al modo de Morales: como una joya «para el reinado dichoso y para la corona de vuestra majestad» y como ejemplo y aviso para el porvenir.

En el Libro III incluye capítulos dedicados a la guerra contra los hijos de Pompeyo en España (XX, 80-81), "Cómo después de la muerte de César se levantaron nuevas alteraciones en España» (XXII, 82), «De la guerra de Cantabria» (XXIV, 84-87). Menciona la presencia de Octaviano en Munda junto a César (cap. XXII, 82): «dio las primeras muestras de valor» pese a tener apenas 18 años. Cap. XXIII, 83: Con el segundo triunvirato, «Octaviano quedó por señor de toda España, y por ello los españoles comenzaron aquí [...] el cuento de sus años, que acostumbran y acostumbramos llamar era del Señor o era de César, así en las historias, escrituras públicas y en los actos antiguos de los concilios eclesiásticos como en particular en las pláticas y conversaciones ordinarias» (plagiando a Garibay, quien a su vez sigue a Dion Casio).

Cuando en el cap. I del Libro Cuarto narra el nacimiento de Cristo, presenta la situación en la España de la época: los españoles «gozaban del sosiego y de los bienes de una bienaventurada paz, cansados de guerras tan largas [...]», paz que era necesaria para acoger a Cristo. «Por esta causa pocas cosas memorables sucedieron en España en tiempo de los emperadores Augusto y Tiberio». Compara el «reinado dichoso» de Felipe II con el de Augusto, «el primero de todos [los emperadores romanos] y el más dichoso [que] mereció nombre de padre de la patria por las excelentes cosas que hizo en guerra y paz» (p. 87). En efecto, en época de Carlos V y Felipe II se consolida la identificación de estos monarcas con Augusto ${ }^{35}$, más visible en los programas iconográficos que en la historiografía; predomina el papel fundamental de Augusto como pacificador del mundo permitiendo así el nacimiento de Cristo y la expansión del cristianismo por los territorios del Imperio Romano, según la idea de antigua tradición cristiana de que la Era o Imperio de Cristo sólo fue posible gracias a la Pax Augusta.

Por otro lado, el De rege et institutione regis (Toledo 1599) de Mariana es un discurso sobre las virtudes del gobernante y la educación del príncipe según el modelo de los viri illus-

33. G. Cirot, Mariana historien, Paris, 1904.

34. Especialmente la edición de F. Pi y Margall, Obras del Padre Mariana, BAE I, Madrid, 1854.

35. J.L. Gonzalo Sánchez-Molero, El erasmismo y la educación de Felipe II (1527-1557), Tesis Doctoral, UCM, Madrid, 1997, 688-689. 
tres; es clara la influencia de tratados anteriores como el De preconiis Hispanie o De praeconiis Hispaniae (1282) de Fray Juan Gil de Zamora, scriptor de la corte de Alfonso X y preceptor del infante don Sancho, futuro Sancho IV el Bravo (ed. José Luis Martín y Jenaro Costas, Salamanca 1997); el Mar de las estorias (o Mar de historias), de Fernán Pérez de Guzmán, Señor de Batres, sobrino del Canciller Pero López de Ayala y tío de Íñigo López de Mendoza, marqués de Santillana (manuscrito de 1401-1500 publicado por primera vez en Valladolid en 1512), o el ya citado Relox de príncipes de Antonio de Guevara (1528). Interesa destacar el Mar de estorias de Pérez de Guzmán ${ }^{36}$, versión en prosa del Mare historiarum del dominico Giovanni Colonna, de mediados del siglo XIV (una historia universal desde los orígenes hasta 1250, fecha de la muerte de Colonna); Pérez de Guzmán dividió su libro en tres partes: retratos de emperadores y príncipes, retratos de sabios y santos, y retratos de reyes, nobles y prelados, siendo ésta la única parte propia, en la que presenta un retrato facetus o jocoso de Augusto, siguiendo a Marcial según el códice descubierto por Boccaccio en Monte Cassino en 1360 y muy difundido por toda Europa desde fines del s. XV ${ }^{37}$.

Un caso especial y curioso en la historiografía española es el que presenta a Augusto como mecenas de la cultura ${ }^{38}$. En 1558, el cronista real Juan Páez de Castro dirigió a Felipe II un Memorial al rey Don Felipe II, sobre las librerías ${ }^{39}$ en el que presentaba la fundación de bibliotecas como un medio eficaz para «ennoblecer una nación» (p. 26) y un programa para la gran biblioteca que el rey quería crear. Proponía localizarla en Valladolid, aunque finalmente el rey decidió instalarla en el recién fundado monasterio de El Escorial ${ }^{40}$.

Para intentar convencer a Felipe de la necesidad y la gloria que supone ser un constructor de bibliotecas, y tras ensalzar la famosa Biblioteca de Alejandría, Páez de Castro (siguiendo a Plinio el Viejo) proporciona ejemplos de grandes personajes de la Antigüedad que fueron fundadores o protectores de bibliotecas (p. 17). En primer lugar, Asinio Polión, creador de la primera biblioteca pública de Roma bajo el cuidado de Varrón [realizando el proyecto de César interrumpido por su asesinato]: cf. Isid., Etym., 6.5.2; Suet., Caes., XLIV. Pero sobre todo Augusto, amante de la poesía y escritor él mismo (Suet., Aug., LXXXV, LXXXIX), quien según Páez (y en esto yerra) fue quien hizo realidad el proyecto frustrado de César erigiendo varias «librerías» en Roma en 33 a.C. bajo el cuidado de Pompeyo Macer (cf. Suet., Caes., LVI): una muy suntuosa [debe referirse a la Biblioteca latina y griega del Templo de Apolo o

36. F. Pérez de Guzmán, Generaciones y semblanzas, ed. de J.A. Barrio Sánchez, Madrid, 1998.

37. Á. Gómez Moreno, España y la Italia de los humanistas. Primeros ecos, Madrid, 1994, 183.

38. Y poeta, como señala el Marqués de Santillana en su Prohemio e carta al Condestable don Pedro de Portugal: cf. Gómez Moreno, España..., op. cit., 154.

39. J. Páez de Castro, Memorial al rey Don Felipe II, sobre las librerías, incluido en Un librito misceláneo y facticio de Páez de Castro (y Juan Bautista Cardona), publicado en 1889, pp. 8-50: http://www.proyectos. cchs.csic.es/humanismoyhumanistas/sites/proyectos.cchs.csic.es.humanismoyhumanistas/files/EL\%20 LIBRITO\%20DE\%20PAEZ\%20DE\%201889.pdf [consultada el 23 de febrero de 2016].

40. G. de Andrés, Real Biblioteca de El Escorial, Madrid, 1970; J.L. Gonzalo Sánchez-Molero, La Librería Rica de Felipe II. Estudio histórico y catalogación, Madrid, 1998. 
Biblioteca Palatina, mencionada por varios autores ${ }^{41}$ ]; otra en la casa de su hermana Octavia [en realidad en el Pórtico de Octavia] (Plut., Marcellus, 30.6; Dion Casio, 49.43.8), y otra en el Capitolio llamada «de los Mayores».

En la tercera parte de este Memorial, Páez de Castro detallaba el programa iconográfico de las salas de la Biblioteca, compuesto por retratos de hombres ilustres paganos y cristianos (según la costumbre romana mencionada por Plinio el Viejo) en función de los temas de los libros alojados en ellas (pp. 35-41). En la primera sala estarían los libros antiguos de Filosofía y Teología; en la segunda los de Geografía, cartas de marear, globos terráqueos, vistas de ciudades, instrumentos de medición, etc., y también las «antiguallas [...] que suelen tenerse en mucho» ${ }^{42}$, "vasos y urnas antiguos de los Griegos y Romanos, que también se pueden contar por antiguallas», retratos de los antecesores del rey, de sabios como Arquímedes, Ptolomeo y Aristóteles, y conquistadores; la tercera sala sería el Archivo, adornado con «retratos antiguos» de César, Augusto «con los tres libros que dexaba escritos al tiempo de su muerte» (según Suet., Aug., LXXXV), Vespasiano y Carlos V. «Las antiguallas se llevarán de Italia, y Sicilia; y en España se suelen hallar sin peligro que sean contrahechas» (p. 45). Y, efectivamente, a las antigüedades italianas traídas por Alonso Chacón (estatuas antiguas de Hesíodo, Eurípides, Aristóteles, Ovidio, Séneca, Plutarco...) se añadieron en la Biblioteca de El Escorial las que Antonio Agustín, Diego Hurtado de Mendoza o el propio Páez de Castro dejaron a Felipe II en legado testamentario junto a libros y manuscritos griegos y latinos de sus librerías ${ }^{43}$.

Este tema de las antigüedades y los retratos de hombres ilustres enlaza con la presencia de Augusto en el coleccionismo y los programas iconográficos de los palacios renacentistas. Como era de esperar, Augusto forma parte de las características series de retratos de emperadores presentes en los palacios de reyes y nobles desde mediados del siglo XIV en Italia, difundidas por toda Europa durante el XVI y XVII ${ }^{44}$. Estas series comprendían la lista canónica de los doce emperadores establecida por Suetonio, que incluía como primer emperador a Julio César, a la que se añadían viri illustres como Escipión, Aníbal, Alejandro Magno y otros emperadores y que solían culminar con el retrato del monarca reinante, Carlos V, Felipe II o ambos, señalando así de forma clara la continuidad dinástica entre el Imperio Romano y el Imperio actual, continuidad cuya realidad histórica se argumentaba y defendía en los

41. Suet., Aug., XVIII y XXIX, 3; Plin. NH, XXXVI, 13, 24-25 y 32, XXXIV, 8, 14; Dion Cas., 53.1.3; Res Gestae Divi Augusti 19 y 24; Ovidio, Trist. III, 1.63; Horacio, Epist. I, 3.17. Cf. C.P. Boyd, Public Libraries and Literary Culture in Ancient Rome, Chicago, 1915, 55 ss.; I. Iacopi - G. Tedone, "Bibliotheca e Porticus ad Apollinis", Röm.Mitt., 112, 2005/2006, 351-378.

42. Augusto también había sido coleccionista de antigüedades: Suet., Aug., LXXII.

43. F. Checa, Felipe II mecenas de las artes, Madrid, 1992, 380-387; G. de Andrés, "Historia de un fondo griego de la Biblioteca Nacional de Madrid. Colecciones: Cardenal Mendoza y García de Loaysa”, RABM, LXXVII, 1, 1974, 5-65. Checa destaca la conjunción de saber y poder político como base de la hegemonía hispánica en época de Felipe II.

44. S. Schröder, "Las series de los Doce Emperadores", en El coleccionismo de escultura clásica en España, Madrid, 2001, 43. 
relatos históricos coetáneos. Encontramos estas series de retratos imperiales que incluyen los de Carlos V y Felipe II en las colecciones del propio Felipe ${ }^{45}$, Martín de Gurrea y Aragón, Duque de Villahermosa, en Zaragoza, Diego Hurtado de Mendoza o Luis de Ávila y Zúñiga, marqués de Mirabel, en Plasencia, todas ellas de mediados del siglo XVI. Así, Luis de Ávila poseía un retrato identificado como de Augusto, hoy perdido, junto a los de otros emperadores y el de Carlos $\mathrm{V}^{46}$. Martín de Gurrea, por su parte, tenía en gran estima un Augusto de mármol, procedente de Zaragoza y también perdido: siendo Gurrea natural de Aragón y vecino de la ciudad era «justo» que hiciese lo imposible «con todo ingenio» para adquirir «la efigie de nuestro fundador», persuadiendo al legítimo propietario (cuyo nombre no dice) ${ }^{47}$.

Uno de los ejemplos más significativos de la presencia de Augusto en los programas iconográficos se relaciona con el príncipe Felipe. Llamado por su padre a Alemania tras la victoria en la batalla de Mühlberg sobre los príncipes protestantes alemanes, el futuro Felipe II emprendió un largo viaje de dos años y medio (1548-1551) - el «felicísimo viaje» - para visitar los territorios del Imperio que estaba destinado a gobernar y afirmar el dominio imperial sobre ellos (norte de Italia, Alemania y Flandes): una demostración del poder de España en una Europa sumida en conflictos políticos y religiosos que fue narrada por Juan Cristóbal Calvete de Estrella y publicada en Amberes en $1552^{48}$. En cada ciudad, salvo naturalmente en las alemanas, y muy especialmente en Flandes, que desde 1531 estaba bajo la regencia de la culta María de Hungría, se le recibió con fiestas, espectáculos y desfiles triunfales, calles adornadas con tapices, conjuntos escultóricos y arquitecturas efímeras que exhibían temas mitológicos y alegóricos y escenas entresacadas de la Historia Antigua y la Historia Sagrada, con claros mensajes políticos alusivos al poder imperial, a la paz y a la unificación política y religiosa de los reinos bajo los Habsburgo, y presentando a Carlos y Felipe como sucesores, por sus virtudes y triunfos, de Escipión Africano, Pompeyo Magno, Vespasiano y Tito, Constantino, Alejandro Magno, Julio César y Augusto ${ }^{49}$. En palabras de Fray Prudencio de

45. Felipe II recibió varias series de retratos como regalo diplomático, herencia y donaciones, hoy dispersas en museos y Sitios Reales. Stephan Schröder sugiere que el retrato de Augusto procedente de la Colección Real actualmente en el Museo del Prado (E 119) formaba parte de una de las dos series de bustos de los Doce Emperadores regalada a Felipe II por el cardenal Ricci da Montepulciano en 1562 o quizá de la donada por Pío V en 1568: Schröder, "Las series...", op. cit., 49.

46. C. Marcks, "Die Antikensammlung des D. Luis de Ávila y Zúñiga, Marqués de Mirabel, in Plasencia", $M M, 42,2001,160$.

47. M. de Gurrea y Aragón, Duque de Villahermosa, Discursos de medallas y antigüedades..., ed. de J.R. Mélida, Madrid, 1902, 121.

48. J.C. Calvete de Estrella, El Felicíssimo viaje del muy alto y muy poderoso Príncipe don Phelippe... [Anvers, 1552], P. Cuenca (ed.), Madrid, 2001 (el amplio "Catálogo de los autores" antiguos y modernos que utilizó en pp. 15-16). Sobre el humanista Calvete de Estrella, discípulo de Hernán Núñez de Guzmán, el «Comendador Griego», y preceptor y bibliotecario del príncipe Felipe, cf. J.L. Gonzalo Sánchez-Molero, "Juan Cristóbal Calvete de Estrella (c. 1510-1593)", en Calvete de Estrella, El Felicíssimo viaje..., op. cit., XVII-L.

49. F.J. Pizarro Gómez, Arte y espectáculo en los viajes de Felipe II (1542-1592), Madrid, 1999, 121 ss. (especialmente 128). Gonzalo Sánchez-Molero, “Juan Cristóbal Calvete de Estrella...”, op. cit., 686-687. 
Sandoval, «no sé que príncipe del mundo ni qué emperadores romanos jamás gozaron de tantas fiestas ni triunfos como los que se hicieron al príncipe en esta jornada.... ${ }^{50}$. Según C.J. Hernando Sánchez, este tipo de viajes político-diplomáticos unían la tradición caballeresca y el retorno a la Antigüedad clásica mediante una puesta en escena teatral (arquitecturas efímeras, procesiones, espectáculos) como forma de manifestación y difusión pública de los intereses políticos y afirmaciones de antigüedad y grandeza; así, el viaje del príncipe Felipe fue «la más acabada imagen ideal del Imperio y de la monarquía española» en su momento de máximo esplendor ${ }^{51}$, recurriendo a la iconografía clásica para presentarse junto a su padre como legítimos representantes y sucesores del Imperio Romano ${ }^{52}$. Es con Carlos V cuando Augusto se convierte en modelo de gobernantes, precisamente por su éxito en la imposición de un poder único en Roma y en la pacificación tras las guerras civiles, que se equiparan a los problemas dinásticos y la división de los territorios heredados por Carlos ${ }^{53}$.

El 11 de septiembre de 1549 Felipe llegaba a Amberes. Del mismo modo que se había hecho en 1520 con motivo de la visita de su padre, se organizaron festejos según un programa iconográfico ideado por el pintor de Su Majestad Imperial Pieter Coecke van Aelst, traductor de Vitruvio y del tratado de arquitectura de Sebastiano Serlio en 1539; la descripción de las fiestas y sus escenarios fue inmediatamente publicada en latín, holandés y francés, ilustrada con xilografías, por el humanista Cornelius Grapheus (Cornelis de Schrijvers) ${ }^{54}$. El programa remitía a la Antigüedad clásica mediante referencias históricas, mitológicas y alegóricas para ensalzar las virtudes físicas, políticas y morales del buen gobernante. Entre los diversos arcos triunfales erigidos por las comunidades extranjeras residentes en Amberes, destaca el Arco de los Españoles, levantado en la calle Hospitalaria al final de una avenida precedida por las Columnas de Hércules (vinculado a la monarquía hispana sobre todo a partir de Carlos $V^{55}$ ) y flanqueada por estatuas de las Virtudes enfrentadas a los reyes españoles que mejor las ha-

50. En su Historia de la vida y hechos del Emperador Carlos V Máximo, Fortísimo, Rey Océano, BAE III, Madrid, 1955, 338-339 (cit. por Gonzalo Sánchez-Molero, "Juan Cristóbal Calvete de Estrella..., op. cit, XVII).

51. C.J. Hernando Sánchez, "Prólogo", en Calvete de Estrella, El Felicíssimo viaje..., op. cit., XIII-XVI.

52. Checa, "Imágenes para un cambio de reinado: Tiziano, Leoni y el viaje de Calvete de Estrella", en Calvete de Estrella, El Felicíssimo viaje..., op. cit., CLXXIII.

53. Un buen ejemplo de esta identificación es el programa iconográfico de la fachada de la Universidad de Salamanca, en el que se representa el ideal político del Imperio unido por la religión, a imagen del poder de Alejandro y de Augusto cimentado en las virtudes de la Prudencia, la Justicia, la Clemencia y la Paz (Pax Christiana). Augusto es considerado por Erasmo «el más magnífico príncipe sobre el más grande pueblo», y así aparece como héroe protagonista de la fachada, retratado en un medallón capite velato (imagen del pacificador y artífice de la reconciliación tras las guerras civiles según P. Zanker, Augusto y el poder de las imágenes, Madrid, 1992, 157): cf. Gabaudan, El mito imperial..., op. cit., especialmente 60, 64, 70, $139 \mathrm{~s}$.

54. C. Grapheus, Spectaculorum in susceptione Philippi Hisp. Prin. Divi Caroli V. Caes. F. An. M.D.XLIX, Antverpiae Aeditorum, Mirificus Apparatus, Antwerp, 1550; Le Triomphe d'Anvers, faict en la susception du Prince Philips, Prince d'Espagn, Antwerp, 1550.

55. Hércules, César, Augusto, Alejandro y Escipión son los protagonistas de los programas iconográficos carolinos: Gabaudan, El mito imperial..., op. cit., 60. 
bían representado (fig. 1). El arco triunfal, seguramente inspirado en los dibujos de arquitectura antigua y contemporánea de Sebastiano Serlio, mostraba en su parte superior un edificio circular que seguía el modelo de los llamados templo de Vesta en Roma y de la Sibila en Tívoli o, más cercanamente, del Tempietto que Bramante diseñó en 1502 por encargo de los Reyes Católicos en San Pietro in Montorio ${ }^{56}$. Siguiendo el detallado relato de Juan Cristóbal Calvete de Estrella en El Felicísimo viaje del muy alto y poderoso príncipe don Phelippe (1550) ${ }^{57}$, este templete representaba el templo de Jano, al que se acerca para cerrarlo, «aviendo constituydo la paz por todo el mundo», el emperador Carlos dando la mano a su hijo Felipe, ambos con armas «a la antigua»; al otro lado del edificio «César Augusto» les muestra el templo que él mismo había cerrado tres veces en su tiempo (Suet., Aug., XXII), a lo que alude la inscripción del arco:

VT QUONDAM AVGVSTVS, NVNC CLAVSIT LIMINA IANI

CAROLVS IN MVLTOS NON RESERANDA DIES.

SIC EST SPERAMVS DOMITO PRIVS ORBE PHILIPPE,

VSQUE SVB IMPERIO CLAVSA FVTVRA TVO ${ }^{58}$

Calvete de Estrella incluía uno de sus epigramas sobre el mismo asunto (II, 128-129):

Pax orbi Princeps, rerum tutela Philippe,

Per te certa venit, Pax colit Herperiam.

Pax habitat terras, Augusti Saecla videntur,

Clauduntur Iani lumina belligeri.

Iamque aetas iterum diffunditur aurea mundo,

Aurea das Princeps Saecula Magne tuis ${ }^{59}$.

56. S. Serlio, I sette libri dell'architettura di Sebastiano Serlio Bolognese, lib. IV, Venezia, 1537, LVIII. El Tempietto de San Pietro in Montorio en lib. III, 1540, XLII ss.

57. Calvete de Estrella, El Felicíssimo viaje..., op. cit., 85-390. Grapheus, Spectaculorum..., op. cit., ff. Er a E4r, xilografía en ff. E2v-E3r.

58. En traducción de Calvete de Estrella, El Felicíssimo viaje..., op. cit., 387: «Como en los tiempos pasados Augusto, assi agora el Emperador Don Carlos ha cerrado la puerta del templo de Jano, de manera que no se abrirá en muchos días, no menos esperamos de vos, serenísimo Príncipe Don Felipe, que habiendo primero sojuzgado el mundo, estará cerrada debajo de vuestro imperio». Gonzalo Sánchez-Molero, El erasmismo..., op. cit., 686-689.

59. En traducción de Calvete de Estrella: «Cierta viene la paz al mundo por vos, Príncipe Don Felipe, que sois amparo y defensa de todos. La paz tiene hecha su asiento en España. La paz habita las tierras. Parece, sin duda, los siglos de Augusto. Ciérrense los umbrales del guerrero Jano, y ya la edad dorada se derrama otra vez por el mundo, porque con vuestro gobierno goza de aquellos dorados y pacíficos siglos»: Calvete de Estrella, El Felicíssimo viaje..., op. cit., 388; Gonzalo Sánchez-Molero, “Juan Cristóbal Calvete de Estrella...”, en Calvete de Estrella, El Felicíssimo viaje..., op. cit., 689. 


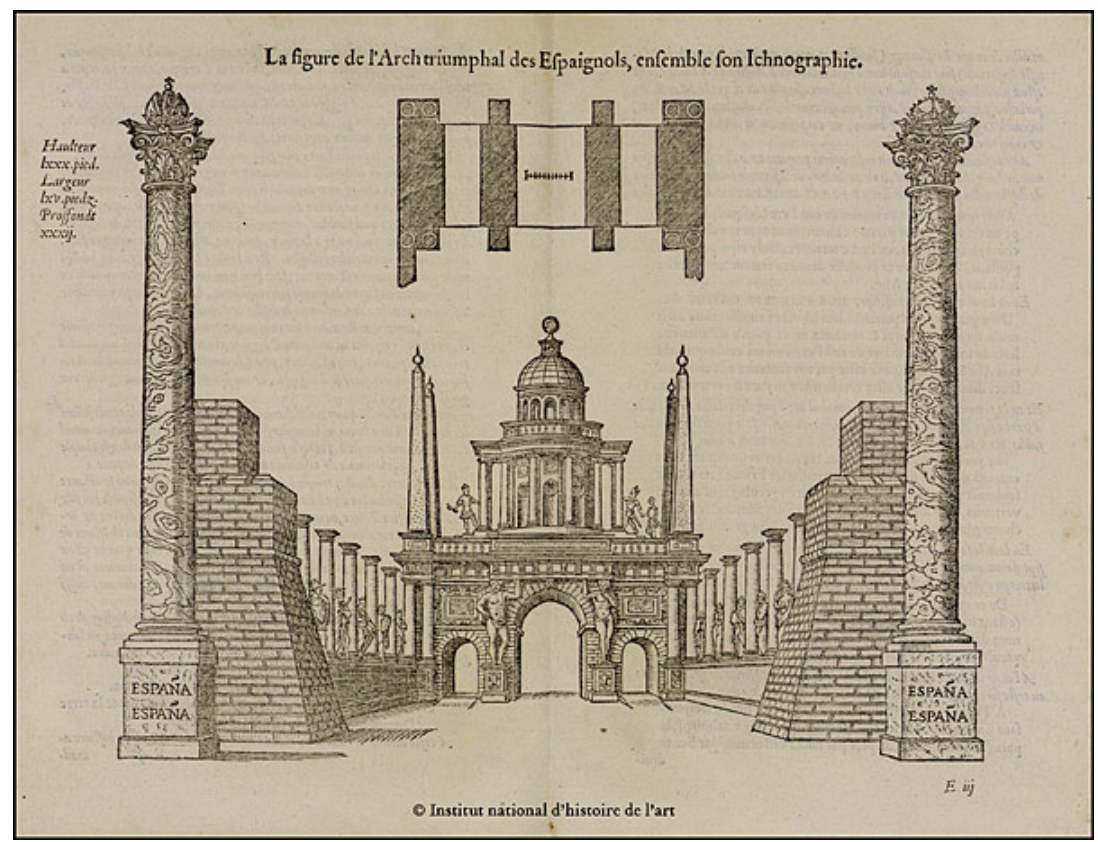

Fig 1. "La figure de l'Arch triumphal des Espaignols, ensemble son Ichnographie", en Cornelius Grapheus, La Très admirable, très magnifique \& triumphante entrée de très haut et très puissant Prince Philipes, prince d'Espaigne, filz de Lempereur Charles Ve [...] en la très renommée, florissante ville d'Anvers, anno 1549 [...] (o Le triomphe d'Anvers, faict en la susception du Prince Philips, Prince d'Espagne), Antwerp, P. Coeck d'Allost et G. Van Dienst, 1550, ff. E2v -E3r.

Fuente: Institut national d' histoire de l'art (INHA, París) http://bibliothequenumerique.inha.fr/viewer/12533/?offset=\#page=45\&amp;viewer=picture.

Diez años después reaparecía la misma idea con motivo del fin de las guerras con Francia, esta vez en forma de medalla conmemorativa de la Paz de Cateau-Cambrésis en 1559 (fig. 2), en cuyo reverso figura de nuevo el templo de Jano con la alegoría de la paz inspirada en una mezcla de reversos de monedas de Augusto y Vespasiano (fig. 3 a y b) ${ }^{60}$. Se representa

60. F.A. Muñoz y E. Díez Jorge, “Pax Orbis Terrarum. La pax en la moneda romana”, Flor. Il., 10, 1999, 220. La utilidad de los reversos de las monedas fue constatada por varios humanistas, sobre todo por Andrea Alciato (Emblemata, Augsburg, 1531, trad. cast. Emblemas, Lyon 1548-1549), Antonio Agustín (Dialogos de medallas, inscriciones y otras antiguedades, Tarragona, 1587) y Cesare Ripa (Iconologia, Roma, 1593). En palabras de Agustín, Diálogos..., op. cit., Diálogo II, 87, los reversos proporcionaban modelos para las composiciones de la Fama, la Discordia, la Paz, la Guerra, la Victoria, etc. y para «las invenciones que muchas veces son menester para ornamento de una fiesta pública en la entrada o coronación de un Príncipe...»". 
la Pax Augusti con la cornucopia en la mano izquierda y la antorcha quemando las armas de los vencidos en la derecha, y una leyenda (PACE TERRA MARIQVE COMPOSITA) que rememora las palabras de Suetonio relativas al episodio del cierre de las puertas del templo tras el fin de las guerras cántabras en 19 a.C.: Ianum Quirinum semel atque iterum a condita urbe ante memoriam suam clausum in multo breviore temporis spatio terra marique pace parta ter clusit (Suet., Aug., XXII, 1).

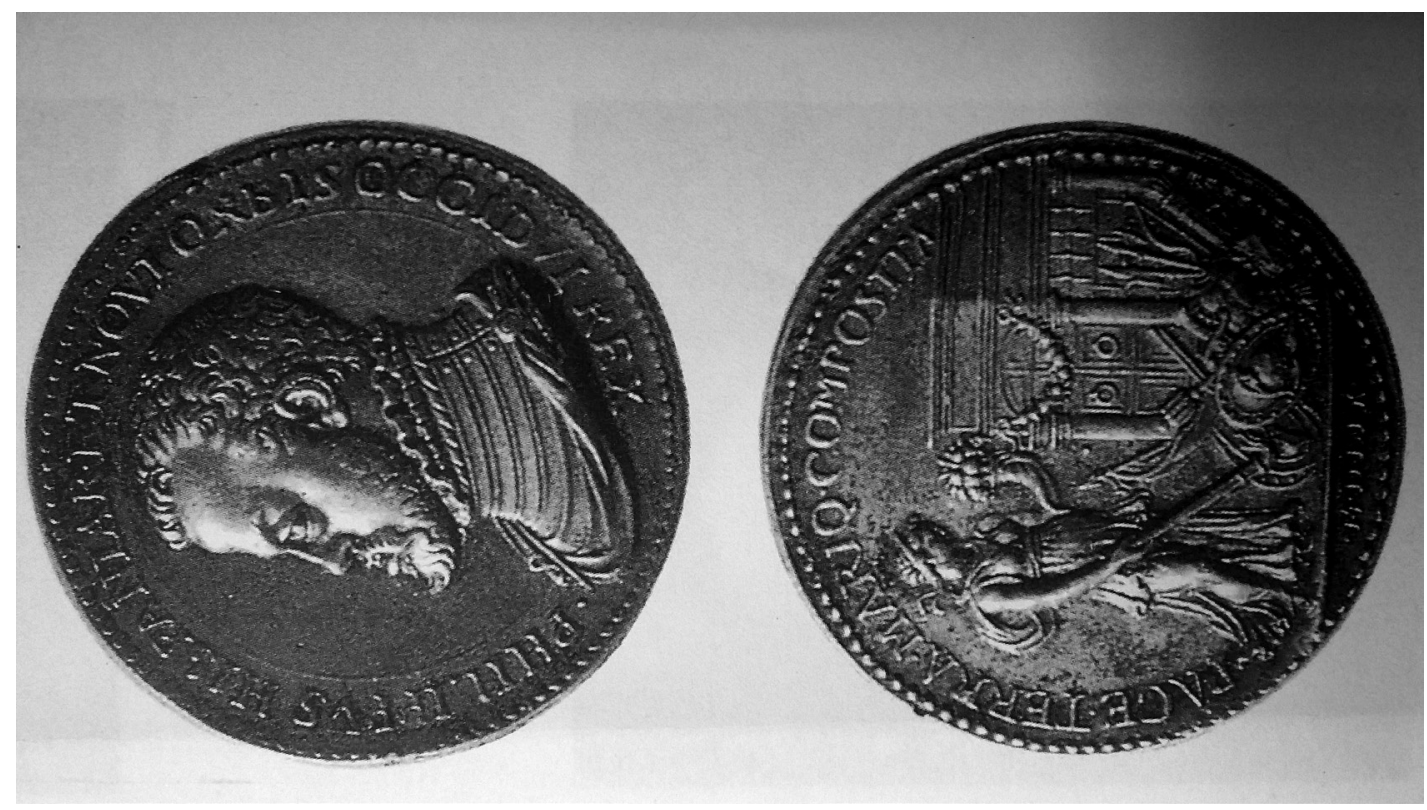

Fig. 2. Medalla alegórica de la Paz de Cateau-Cambrésis, firmada entre Felipe II y Enrique II de Francia el 3 de abril de 1559, obra del escultor y orfebre florentino Giovanni Paolo Poggini. De F. Checa, Felipe II mecenas de las artes, Madrid, 1992, 108.

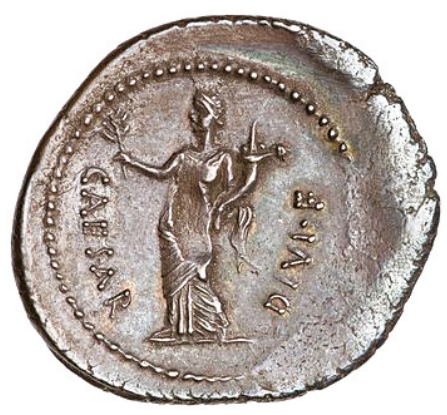

Fig. 3a. Denario de Octaviano (reverso), 32-29 a.C. (RIC I, Augustus 252). Colección: American Numismatic Society 1947.2.411. Fuente: http://numismatics.org/ocre/id/ric.1(2).aug.252

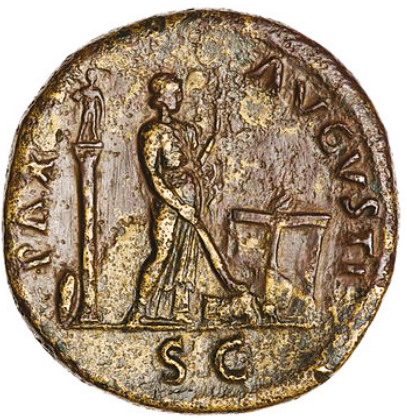

Fig. 3b. Sestercio de Vespasiano (reverso), 71 d.C. (RIC II, Part 1, Vespasian 95). Colección: American Numismatic Society 1995.11.52. Fuente: http://numismatics.org/ocre/id/ric.2_1(2). ves.95numismatics.org/ocre/id/ric.1(2).aug.252 


\section{Conclusión}

El papel de Augusto en las historias de España comentadas no resulta ser tan relevante como el de otros personajes de la historia de Roma como Escipión, César o Trajano, o incluso otros que no tuvieron nada que ver con Hispania (los «reyes gentiles» Alejandro, Darío y Artajerjes, por ejemplo) pero sí con el cristianismo, como Constantino. De hecho César tiene una gran presencia en la historiografía española por su victoria en Hispania frente a los hijos de Pompeyo y como fundador de ciudades, asuntos a los que los historiadores y cronistas dedican bastante espacio. Las historias y crónicas de España mencionan a Augusto en relación a dos episodios tomados de Suetonio: como acompañante de César en la campaña contra los hijos de Pompeyo, concretamente en la batalla de Munda del 45 a.C. (VIII, 1) - algunas historias incluyen el prodigio de la palmera de la que brotan retoños en los que extrañamente anidarán palomas (XCIV) -, y en la guerra contra los cántabros (27-19 a.C.), que pone fin a la conquista (XX; XXI, 1). Podríamos decir que Augusto es un personaje secundario, que sería irrelevante salvo por tres circunstancias o particularidades que poco tienen que ver con su papel como creador de un nuevo régimen y fundador del Imperio.

En efecto, esta relevancia deriva de dos factores estrechamente relacionados. En primer lugar, por su relación con el nacimiento de Cristo al ordenar el censo, y como restaurador de la paz (Pax Romana o Pax Augusta) tras poner fin a las últimas guerras de conquista (Cantabria, Aquitania, Panonia, Dalmacia e Iliria, según Suet., Aug., XXI, 1, aunque los historiadores españoles sólo citan la campaña contra los cántabros, astures y vacceos o sólo los cántabros), por lo que mandó cerrar las puertas del templo de Jano en Roma (Suet., Aug., XXII, 1).

En segundo lugar, esta pax Romana lograda por Augusto se identifica como pax Christiana, puesto que el fin de las guerras permitió (según estos historiadores, excepto Morales) la promulgación de un edicto en Tarragona - hecho en el que insiste mucho Margarit, por ejemplo - ordenando el censo de todos los habitantes del Imperio, por lo que pudo cumplirse la profecía del nacimiento de Cristo en Belén y la salvación del mundo.

Así, Augusto aparece como el pacificador, el creador de la primera unidad política de España: representa el fin de la conquista de Hispania, el dominio de Roma paralelo a la pérdida de la independencia de los pueblos hispanos tras someter a los últimos rebeldes, los cántabros. Por tanto aparece indisolublemente unido a la idea de la unidad de España, que empieza con este dominio de Roma. Idea que se retoma en diversos momentos de la historia que presentan conflictos internos, como los reinados de Alfonso X, Felipe II y Felipe IV y, singularmente, tras la victoria de Franco sobre los «explotadores de la República» que se celebró con retraso en 1940 con ocasión del Bimilenario de Augusto ${ }^{61}$. Sin que resulte contradictorio, todos los cronistas insisten en reconocer los beneficios de la romanización (unidad, prosperidad, civilización) que compensan la pérdida de la libertad, al tiempo que ensalzan las

61. Fernando Valls Taberner en los Quaderni Augustei. Studi stranieri XVIII, 1939, cit. por J. García Sánchez, "Roma y las academias internacionales", en R. Olmos, T. Tortosa y J.P. Bellón (eds.), Repensar la Escuela del CSIC en Roma. Cien años de memoria, Madrid, 2010, 92. Sobre esta celebración remito al excelente texto de Antonio Duplá en este mismo volumen. 
virtudes esenciales de los hispanos: heroísmo, amor a la independencia, austeridad y buenas costumbres, junto a defectos como la desunión.

Por todo ello, en los tratados de educación de príncipes (como el Relox de príncipes o la Epístolas familiares de Antonio de Guevara), Augusto es modelo para la paz, paradigma del buen gobernante tanto en los Mirabilia como en la historiografía; figura respetada por los historiadores cristianos primitivos por haber procurado el siglo de oro anunciado por Virgilio en su cuarta Égloga y por diversos sueños y presagios que precedieron, acompañaron y sucedieron al nacimiento de Augusto como anuncios de su futura grandeza recogidos por Suetonio (Aug., XCIV a XCVII) ${ }^{62}$.

Estos temas ligados a Augusto, introducidos y desarrollados por la historiografía bajomedieval y renacentista, explican la representación de Augusto en los programas iconográficos de Carlos V y Felipe II, y perdurarán como topoi en las Historias de España posteriores.

62. Gómez Moreno, España..., op. cit., 244-245. 